Luiz Fernando de Souza

Um Palco para o Conto de Fadas: uma experiência teatral com crianças na educação infantil

Dissertação apresentada como requisito parcial para obtenção do grau de Mestre pelo Programa de Pós-graduação em Educação do Departamento de Educação da PUC-Rio.

Orientador: Prof. Leandro Konder

Rio de Janeiro abril de 2004 
Luiz Fernando de Souza

\section{Um Palco para o Conto de Fadas: uma experiência teatral com crianças na educação infantil}

Dissertação apresentada como requisito parcial para obtenção do grau de Mestre pelo Programa de Pós-graduação em Educação do Departamento de Educação do Centro de Teologia e Ciências Humanas da PUC-Rio. Aprovada pela Comissão Examinadora abaixo assinada.

Prof. Leandro Konder

Orientador

Departamento de Educação - PUC-Rio

Prof. Maria Luiza M.B. Oswald Departamento de Educação - PUC-Rio

Prof. Vera Maria Ramos de Vasconcellos

UERJ

Prof. Paulo Fernando C. de Andrade Coordenador Setorial do Centro de Teologia e Ciências Humanas

Rio de Janeiro, 12 de abril de 2004 
Todos os direitos reservados. É proibida a reprodução total ou parcial do trabalho sem a autorização da universidade, da autora e da orientadora.

\section{Luiz Fernando de Souza}

Luiz Fernando de Souza graduou-se em Artes Cênicas pela UniRio em 1984. Desde 1993 exerce a função de Professor de Teatro na Creche Fiocruz, no Rio de Janeiro. Em 2001 tornou-se especialista em Educação Infantil pela Pontifícia Universidade Católica Puc-Rio apresentando a Monografia "Abre o Pano para as Rosas do Porvir". Em 2004 concluiu o Curso de Mestrado em Educação na Puc-Rio apresentando a dissertação "Um Palco para o Conto de Fadas - Uma Experiência Teatral com Crianças na Educação Infantil". Desde 1997 é professor do Curso de Desenvolvimento Profissional para Educador Infantil da Creche Fiocruz/Escola Politécnica Joaquim Venâncio. Em 1997 foi professor na Faculdade de Educação da Baixada Fluminense da UERJ na disciplina Recreação.

Ficha catalográfica

\section{Souza, Luiz Fernando de}

Um palco para o conto de fadas : uma experiência teatral com crianças na educação infantil / Luiz Fernando de Souza; orientador: Leandro Konder. - Rio de Janeiro : PUC-Rio, Departamento de Educação, 2004.

86 f. : il. ; $30 \mathrm{~cm}$

Dissertação (mestrado) - Pontifícia Universidade Católica do Rio de Janeiro, Departamento de Educação

Inclui referências bibliográficas

1. Educação - Teses. 2. Teatro. 3. Arte. 4. Educação. I. Konder, Leandro. II. Pontifícia Universidade Católica do Rio de Janeiro. Departamento No FNıırarãn III Títıln 
Esse trabalho é especialmente dedicado ao meu grande amigo Joselito Vilela que, enquanto vivo, me proporcionou momentos de profunda alegria e solidariedade. Vítima de um ato covarde de barbárie, repousa quieto em meu coração, na minha memória e na de todos que com ele conviveram. Que este trabalho possa servir como mais um tijolo na construção de um mundo melhor, onde as diferenças entre os seres sejam realmente respeitadas. Um grande beijo Lito, onde você estiver! 


\section{Agradecimentos}

Após dois anos de estudos chegou afinal o momento tão esperado de obter o sonhado grau de mestrado em Educação. Essa jornada só se tornou possível graças a grandes encontros que me foi dado pela sorte realizar. Nesse momento, cabe agradecer a esses companheiros de caminhada:

Ao grande professor Leandro Konder que, mais que um Mestre, se tornou um símbolo que sempre recordarei com alegria, respeito, admiração.

Às grandes mestras, $\operatorname{Prof}^{\mathrm{a}} \mathrm{Dr}^{\mathrm{a}}$ Vera Vasconcelos, profundamente liga à história da Creche Fiocruz, pelo constante incentivo à nossa produção de conhecimento e Prof $^{a} \operatorname{Dr}^{\mathrm{a}}$ Maria Luisa Oswald, pelo carinho, cuidado, bom-humor que sempre demonstrou por todos os alunos. Obrigado por terem aceito o convite para participar da minha banca.

A todos os colegas e professores da PUC-Rio, em especial à Prof $^{a}$ Dr $^{a}$ Sonia Kramer, por acreditar que eu tinha chance de ser aprovado no Curso de Mestrado. Além das Prof ${ }^{\mathrm{a}} \mathrm{s} \mathrm{Dr}^{\mathrm{a}} \mathrm{s}$ Alicia Bonamino, Isabel Lélis, Zaia Brandão, Menga Ludke, Rosália Duarte, Rita Ribes, Solange Jobim, Vera Candau, pelo carinho, amizade, troca de idéias, conselhos e principalmente, pela enorme admiração que souberam criar no meu coração pelo seu trabalho em prol do avanço do conhecimento.

À minha família: minha mãe Irene, minha irmã Judith, meu sobrinho Lucas, minha tia-avó Aretusa, meu cunhado Sávio, que sempre me consolam nos momentos de tristeza e me alegram com conselhos e apoio. 
À minha grande amiga-irmã Yvone Souza, que sempre me aponta caminhos, antes mesmo de eu poder compreender o significado da indicação. Sempre companheira, eterna lutadora pelos direitos da infância.

À minha queridíssima amiga Ângela Ribeiro que tem me ajudado a rever tudo o que escrevo e que, com seus conselhos e enorme paciência, tem contribuído para a melhoria desse trabalho.

À minha querida amiga "chefe" Silvia Motta, que mesmo passando por momentos turbulentos em sua vida, não perde o bom humor, a simpatia, a elegância e a solidariedade.

À minha amiga Maura pela parceria nos momentos difíceis.

À minha amiga Késia, que luta contra muitos obstáculos para manter o sonho de cuidar e educar as crianças pequenas da creche Fiocruz.

À minha amiga Lenir que está sendo um ombro amigo num momento difícil de minha vida.

À todas vocês agradeço, pois mesmo após sofrer toda espécie de calúnia, ataques covardes, inveja irracional, vocês continuam alegres, elegantes, inteligentes e amigas. Obrigado pelos conselhos e pelo apoio de todas as horas.

A todos os colegas da creche Fiocruz que apesar dos momentos tristes que vivemos, em especial em 2001, estou certo que conquistei seu respeito, amizade, carinho. Sem todos vocês o nosso trabalho na creche nada significaria.

À Fundação Oswaldo Cruz (Fiocruz),em especial à Dr ${ }^{\mathrm{a}}$ Márcia Teixeira, que em sua gestão à frente da DIREH (Diretoria de Recursos Humanos da Fiocruz) pude realizar o sonho de concluir o curso de Mestrado.

Aos meus amigos da ASFOC (Associação dos Funcionários da Fundação Oswaldo Cruz), em especial à $\operatorname{Prof}^{a} \operatorname{Dr}^{\mathrm{a}}$ Rita Mattos, pelo apoio e conselhos durante as lutas travadas por melhores condições de trabalho. 
Aos amigos da EPSJV (Escola Politécnica de Saúde Joaquim Venâncio), em especial à Prof ${ }^{a} \operatorname{Dr}^{\mathrm{a}}$ Isabel Brasil, extensivo ao seu companheiro o $\operatorname{Prof}^{\mathrm{o}} \operatorname{Dr}^{\mathrm{o}}$ André Bueno, que, sem seu apoio e incentivo, não teria sido possível a realização desse trabalho.

Aos amigos da ENSP (Escola Nacional de Saúde Pública), em especial à Fátima Pivetta, que tem ocupado cada vez mais espaço em meu coração pelas demonstrações de ternura, apoio e solidariedade.

Ao meu querido amigo Osvaldo que com seus conselhos e apoio me ensina a ver o mundo de uma forma mais emocionada.

Aos grandes amigos de todas as horas: Paulo Longo, Fernando, Cleber, Marcelo, Charles, Henrique, Sérgio, Platão, Jonatas, Alisson, Paulinho César e muitos outros.

À minha querida amiga Claudia Teixeira que muito me ajudou com conselhos e advertências a respeito da metodologia e fundamentação desse trabalho.

Agradeço ao Eduardo que, recém-chegado ao meu coração, contribuiu com sua sabedoria, inteligência e solidariedade para que esse trabalho tivesse menos erros que porventura ainda tenha.

A todas as crianças que foram sujeito de investigação dessa pesquisa e para quem, afinal, ela é dedicada. 


\section{Resumo}

Souza, Luiz Fernando de; Konder, Leandro. Um palco para o conto de fadas: uma experiência teatral com crianças na educação infantil. Rio de Janeiro, 2004. 86p. Dissertação de Mestrado - Departamento de Educação, Pontifícia Universidade Católica do Rio de Janeiro.

A presente Dissertação de Mestrado busca construir uma base epistemológica consistente para uma experiência teatral, exercida freqüente e organizadamente, com crianças pequenas de diferentes culturas, religiões e extratos sociais, numa creche institucional do Rio de Janeiro. Quer-se discutir a possibilidade de trabalhar dramaturgicamente os contos de fadas, partindo do pressuposto de que tais narrativas fantasiosas possuem um profundo valor antropológico, social e histórico e que o exercício de sua encenação pode ser um instrumento de construção do conhecimento no espaço Creche, além de ajudar a criança a se constituir como sujeito livre, criativo e expressivo, compreendendo o contexto social no qual é inserida pelo nascimento, valorizando a aquisição do conhecimento sensível e a troca afetiva com o outro, reconhecendo-o como parceiro fundamental no desenvolvimento da linguagem, da consciência individual e da cidadania. Inicialmente buscou-se diálogo com autores como Bakhtin, Benjamin, Bettelheim, Bourdieu, Fischer, verificando como a teoria se ancora na prática de encenação teatral com crianças de 0 a 6 anos. Foi considerado também o fato das Artes Cênicas desenvolver tanto a linguagem corporal (imagem) como o imaginário da criança. A conclusão desse estudo evidenciou a necessidade de se estabelecer um palco para o conto de fadas, no qual o contato com a narrativa fantasiosa e o exercício de sua encenação, possam contribuir para construção de alternativas sensíveis em contraponto ao conhecimento mais racional, sem, no entanto, negá-lo, para que a criança, desde pequena, aprenda a ver o mundo como algo a ser modificado no presente, posto que tem um passado, que pode ser revisto.

\section{Palavras-chave}

Arte, Corpo, Contos, Criança, Cultura, Educação, Linguagem, Teatro. 


\section{Abstract}

Souza, Luiz Fernando de; Konder, Leandro (Advisor). An Stage for Fairytales - A Theatrical Experience with Children in Child Education". Rio de Janeiro, 2004. 86p. MSc. Dissertation Departamento de Educação, Pontifícia Universidade Católica do Rio de Janeiro.

This Master dissertation aims to build a solid epistemological basis for a drama experience, frequently performed by young children from different cultures, religions and social classes in an institutional kindergarten in Rio de Janeiro. The point is to try to dramatize the fairy tales, based on the fact that these fantastic narratives have great anthropological, social and historical value and its staging can be an instrument to construct knowledge in Education, besides helping the child to understand herself as free, creative and expressive person, comprehending the social context in which she was born, giving value to the acquisition of sensitive knowledge and the affection between people, recognizing them as partners in the development of Language, self-conscience and citizenship. In the beginning, we look for a dialogue with authors such as Bakhtin, Benjamin, Bettelheim, Bourdieu, Fischer, trying to verify if the theory can help in the practice of this theatrical experience with young children. It was considered also the fact that dramatization can develop the corporal language (image) as long as the child's imagination. In the conclusion of this study we tried to show the need to stabilize a "stage" to the fairy tales in which the contact with the fantastic narrative and its dramatic performance, can contribute to construct sensitive alternatives in opposition to rational knowledge, without denying it, in order to make the child to learn how to see the world as something that can be modified in the present, since it has a past that can be critized.

\section{Keywords}

Art, Body, Tales, Child, Culture, Education, Language, Theater. 


\section{Sumário}

1. Introdução -

2. Fundamentação Teórica ----1.--- 17

2.1. Diálogo I - Do Primitivo à Criança Contemporânea: o teatro como

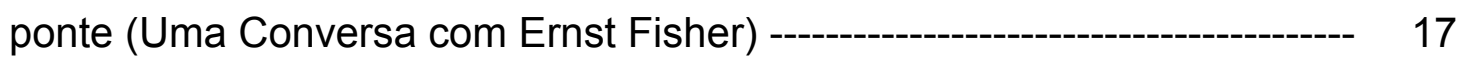

2.2. Diálogo II - A Importância dos Contos de Fadas (Conversando com

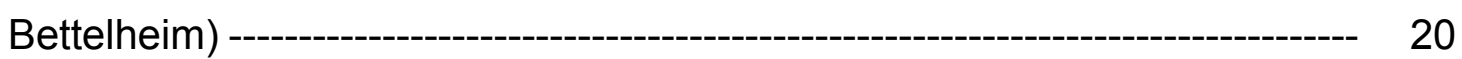

2.3. Diálogo III - Uma Conversa com Benjamin sobre o Teatro Infantil

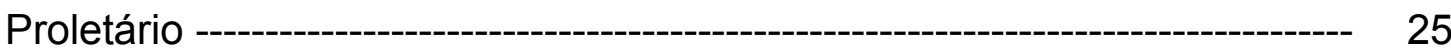

2.4. Diálogo IV - O Círculo Encantado de Bakhtin: Teatro, Educação e Vida

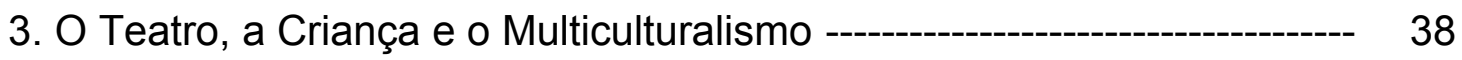

4. O Teatro e o Corpo da Criança --

5. Uma Experiência Teatral com Crianças Pequenas: Indicações Metodológicas

6. Conclusão -

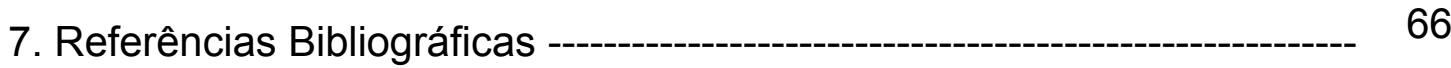

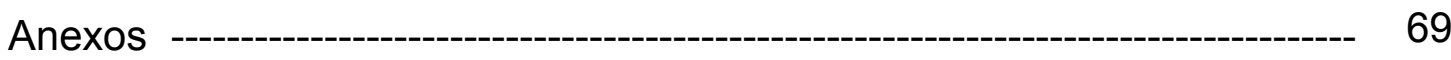

Anexo A - Projeto de Teatro/Expressão Corporal ------------------------- 70

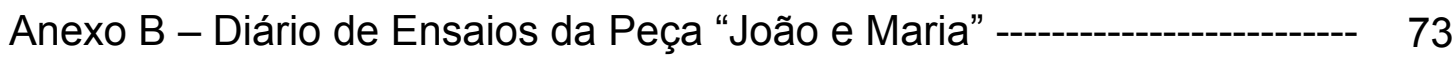

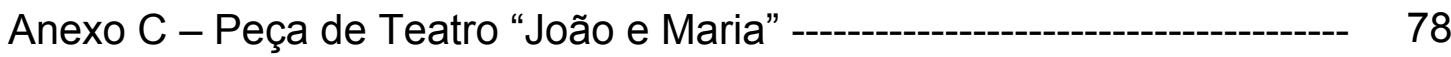

